\title{
Evaluation of Reclaimed Hydrated Fly Ash as an Aggregate for Sustainable Roadway Base Material
}

\author{
Mark H. Wayne, ${ }^{1}$ David J. White, ${ }^{2}$ Jayhyun Kwon $\mathbb{D},{ }^{3}$ and Jacek Kawalec $\mathbb{D}^{4}$ \\ ${ }^{1}$ Tensar International Corporation, Alpharetta, GA 30009, USA \\ ${ }^{2}$ Department of Civil Construction and Environmental Engineering, Iowa State University, Ames, IA, USA \\ ${ }^{3}$ Kennesaw State University, Marietta, GA 30060, USA \\ ${ }^{4}$ Tensar International Limited, Blackburn, UK \\ Correspondence should be addressed to Jacek Kawalec; kawalec@tensar.pl
}

Received 29 May 2019; Revised 7 December 2020; Accepted 23 December 2020; Published 7 January 2021

Academic Editor: Jingfeng Yuan

Copyright (c) 2021 Mark H. Wayne et al. This is an open access article distributed under the Creative Commons Attribution License, which permits unrestricted use, distribution, and reproduction in any medium, provided the original work is properly cited.

\begin{abstract}
This paper summarizes the findings from laboratory and field performance testing of reclaimed hydrated class C fly ash (HFA) stabilized with a triangular aperture geogrid. This phase of testing was performed on HFA laboratory specimens and field test sections. The laboratory test results provided estimates for design input values, while the field testing assessed performance characteristics including the as-constructed modulus of the subgrade reaction, the in situ resilient modulus, and permanent deformation. For the laboratory portion, all results were derived from tests conducted on specimens immediately after sample preparation and after a 7-day cure. The compressive strength of reclaimed hydrated class C fly ash increases with curing. The strength of the HFA material can be further increased when mixed with a chemical stabilizer. For this project, chemical stabilization with lime was not viable because the lime supplier was too far from both HFA source and project site. Based on cyclic plate load tests, the in situ resilient modulus of the HFA and geogrid-stabilized HFA layers were determined on site. This paper reports the findings from the laboratory and field plate load test and highlights the potential use of geogrids in the stabilization of HFA.
\end{abstract}

\section{Introduction}

In many locations across the globe, subgrade soils are, in general, not suitable for use as a pavement foundation, and a suitable fill is difficult to find in many instances. So, depending on regions, anthropogenic materials like blast furnace slags and burnt and unburnt mining wastes (clay shales) are more often used for construction as reported by Haibin and Zhenling [1], Ebrahimi, et al. [2], Rafalski and Wilczek [3], Akbarnejad, et al. [4], and Hainin, et al. [5]. The key to success is the long-term stability of such materials due to possible mineralogical changes reported by Adamczyk et al. [6]. Also, reclaimed hydrated class C fly ash (HFA and market name C-stone), which is produced by Headwaters Resources, Inc. [7], has been used as a road base material or as a select fill for rigid and flexible pavements. Reclaimed hydrated class $\mathrm{C}$ fly ash has pozzolanic properties and therefore is able to gain strength over time when moistened and compacted. The use of reclaimed hydrated fly ash provides environmental benefits by reuse of waste products, as reported by Zabielska-Adamska [8].

Research done by Bergeson and Barnes [9] demonstrated that the compressive strength of the reclaimed hydrated class C fly ash base can increase from zero to as much as $50 \mathrm{psi}$ within 7 days of curing. Furthermore, research by Bergeson and Barnes [9] and White [10] documents strength increases and improved long-term durability of reclaimed hydrated fly ash when mixed with chemical stabilizers such as raw fly ash and hydrated lime. Compressive strength test results show that the addition of $10 \%$ raw fly ash could increase the compressive strength by $80 \%$ compared to the untreated reclaimed ash, while the addition of $2.5 \%$ hydrated lime could increase the strength of the reclaimed ash by 8 times. Based on the laboratory test results, Bergeson and Barnes [9] 
determined layer coefficients for reclaimed hydrated class $\mathrm{C}$ fly ash base for use in AASHTO flexible pavement design as a function of layer thickness.

Senadheera et al. [11] investigated strength characteristics and microstructure of hydrated fly ash to evaluate the suitability of the material as a flexible base material. The study found that the reclaimed fly ash was crushed during compaction, but it gained strength after placement due to the hydration and formed a stiff layer. To prevent moisture loss during hydration, the researchers recommended the application of asphalt emulsion after compaction as the curing moisture is crucial to the microstructure formation of hydrated fly ash.

As a lime supplier was located too far from the project site, mechanical stabilization of the HFA using geogrid was proposed as opposed to traditional chemical stabilization. The inclusion of geogrid in pavement structures has long been accepted to improve the performance of aggregate base course. A hypothesis employed in this trial is that the geogrid synergistically interacts with the HFA during construction in such a way that the HFA obtains its optimal engineering properties so that the performance of the HFA is maximized. When the HFA layer is in service, the composite consisting of HFA and geogrid has enhanced properties over those of the original host material.

The objective of this study was to evaluate the performance of the mechanically stabilized HFA and provide design related input properties, such as the strength or modulus of mechanically stabilized HFA. Resilient modulus of the HFA is not performed as the untreated HFA has not been considered as a suitable alternative to the crushed rock base materials. Pavement design guide with reclaimed HFA is based on the 28-day compressive strength of HFA stabilized with fly ash or hydrated lime. Typical resilient modulus of crushed rock aggregate base course ranges from 100 to $200 \mathrm{MPa}$. In order to use the untreated HFA as an aggregate, the mechanically stabilized HFA should achieve resilient modulus values higher than $100 \mathrm{MPa}$.

A series of laboratory testing was conducted on both untreated and mechanically stabilized HFA specimen. Further, field test sections were constructed containing three different test items. The field test program included two untreated control test items and one mechanically stabilized HFA for performance comparison. Field plate load tests confirmed that the construction of an HFA mechanically stabilized layer resulted in a composite that exhibited increased strength development in a shorter period of time.

\section{Laboratory Test Program}

A total of four triaxial test specimens were tested using an HFA marketed material known as C-stone and produced by Headwaters Resources, Inc. Material composition is provided on the manufacturer's website and is not discussed in detail within this paper apart from basic chemical composition and engineering properties as shown in Table 1. It is noted that tests were conducted in series - resilient modulus and quick shear strength tests followed by permanent deformation testing. The former tests were conducted in accordance with AASHTO T307 protocol [12] and the latter using procedures found in NCHRP 598. Permanent deformation tests were conducted on an independently remolded test specimen in order to assess the materials resistance to long-term rutting behavior.

To investigate the effect of geogrid on modulus and permanent deformation behavior of C-stone, two samples were prepared with geogrid placed at mid-depth of the sample. One control and one geogrid-stabilized sample were tested without curing and the other two samples (one control and one geogrid-stabilized sample) were cured for 7 days to investigate the curing effect on strength. Mechanical properties of the geogrid used in this study are summarized in Table 2.

Grain-size distribution curve (Figure 1), Standard Proctor, and laboratory California bearing ratio (CBR) values (Figure 2) were established for the C-stone used in this study. Based on the conceptualized construction specification, a pretest target of 98 percent Maximum Dry Density (MDD) at the optimum moisture content (OMC), as determined by ASTM D698, was established for remolding specimens in the laboratory for characterization testing and evaluation. The source material contained in excess of $25 \%$ fines. Triaxial specimens were remolded in a 150-millimeter diameter split mold using a manual Modified Proctor hammer. Once testing was initiated, the lab reported that the intended 98\% MDD value could not be achieved due to the fact that the full aggregate sample was tested in a large-scale test and only the 19.05 millimeter minus material was used for the development of the proctor curve. As such, a maximum effort yielded a compacted dry density of $96 \%$ MDD, and this density value was targeted for all testing in order to provide useful comparisons between tests and treatments.

2.1. Resilient Modulus (AASHTO T307). The resilient modulus test was conducted in accordance with procedures contained within the referenced test standard. The specimen was subjected to a series of load pulses at a variety of axial stresses and confining pressures (15 specific combinations of stress levels), and recoverable deformation resulting from these load pulses were recorded. The data is used to fit a constitutive model, where resilient modulus can be predicted for any level of stress the pavement designer wishes to consider in his/her design. The predictive moduli are plotted in Figure 3 to compare values associated with specimen prepared using differing curing and reinforcement conditions. The data graphically depicted in Figure 3 are generated based on the universal model.

The 0-day cure results demonstrated that the geogrid had a minimal influence on stiffness properties. This is most likely due to the fact that the $\mathrm{C}$-stone did not begin to engage with the geogrid. In contrast, Figure 3(b) indicates that curing time does tend to have an effect. The time allowed for curing (7 days) produces a material approximately $10-25 \%$ stiffer (with no grid reinforcement) and 25-60\% stiffer (with the geogrid). These relative improvements indicate that the C-stone material possesses cementitious bonding behavior 
TABLE 1: Chemical constituent and engineering properties of the HFA [7].

\begin{tabular}{lc}
\hline Chemical composition & Mass percentage (\%) \\
\hline Silicon dioxide $\left(\mathrm{SiO}_{2}\right)$ & 26.81 \\
Aluminum oxide $\left(\mathrm{Al}_{2} \mathrm{O}_{3}\right)$ & 15.94 \\
Ferric oxide $\left(\mathrm{Fe}_{2} \mathrm{O}_{3}\right)$ & 5.21 \\
Calcium oxide $(\mathrm{CaO})$ & 22.45 \\
LOI (loss on ignition) $950^{\circ} \mathrm{C}$ & 18.96 \\
\hline Engineering properties & 1.5 \\
Bulk specific gravity & 1440 \\
Dry unit weight $\left(\mathrm{kN} / \mathrm{m}^{3}\right)$ & $<55$ \\
Los Angeles abrasion (AASHTO T96), grading B, loss \% & \\
\hline
\end{tabular}

TABLE 2: Summary of geogrid material mechanical properties.

\begin{tabular}{lccc}
\hline Property & Test method & Units & Minimum value \\
\hline Aperture shape & Observation & Triangular \\
Aperture size (longitudinal $\times$ diagonal direction) & Direct measurement & $\mathrm{kN}(\mathrm{m})$ & $40 \times 40$ \\
Radial stiffness at 0.5\% strain, min. & ASTM D6637-11 & $\%$ & 300 \\
Junction efficiency & ASTM D7737 & 93 \\
\hline
\end{tabular}

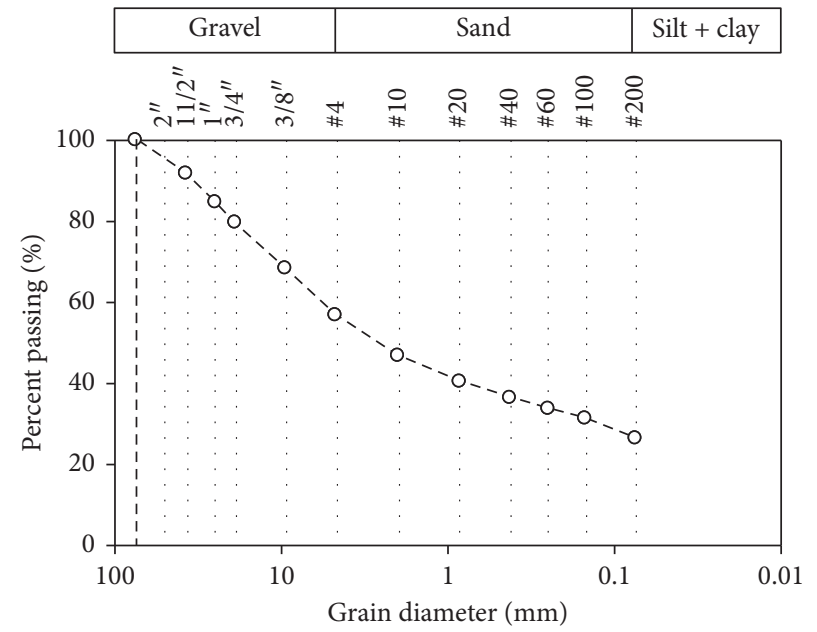

Figure 1: Hydrated class C fly ash (C-stone) grain-size distribution curve.

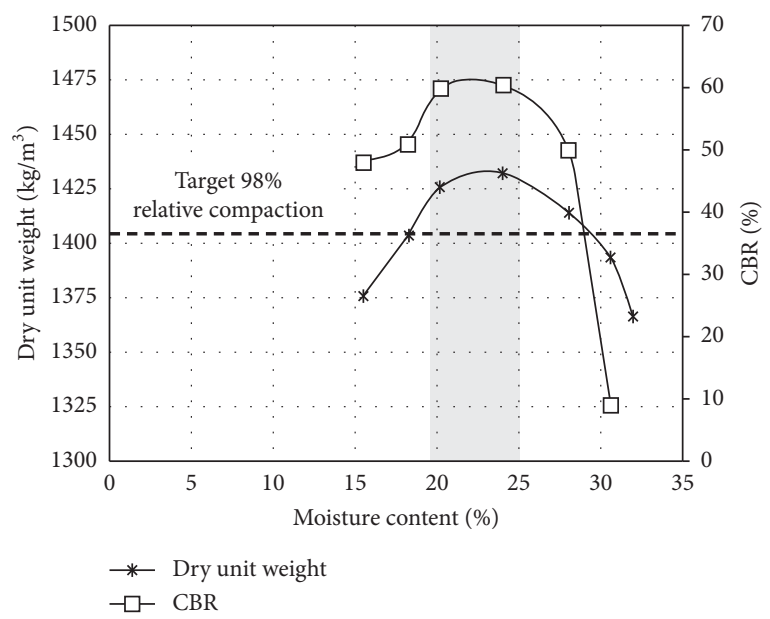

Figure 2: Standard Proctor and California bearing ratio results. which is enhanced by the inclusion of the geogrid. It is postulated that this is due to a higher level of locked-in lateral stress that is generated as a result of the inclusion of the geogrid. This residual stress allows the particles to remain in contact with one another, allowing stronger bonds to be established during the pozzolanic reaction. The generation of locked-in lateral stresses was initially reported by White et al. [13] and substantiated by the work of Wayne et al.[14].

Bergeson and Barnes [9] provided HFA structural layer coefficients $\left(a_{i}\right)$ for use in the design of flexible pavement. A structural layer coefficient is an abstract number that represents the relative strength of the construction materials in the 1993 AASTHO procedure [12]. In pavement design, the design strength of the self-cementitious and pozzolanic materials increased with an increase in thickness. In general, semirigid or rigid layers have California bearing ratio (CBR) values greater than $100 \%$. Therefore, the layer coefficient of the semirigid or rigid layer can be estimated using the correlation of unconfined compressive strength and layer coefficient. The suggested layer coefficients for untreated HFA ranged from 0.12 to 0.19 , depending upon the layer thickness. For 150 millimeters of untreated HFA base, the layer coefficients ranged from 0.13 to 0.13 , while layer coefficients for 300-millimeter thick untreated HFA ranged from 0.18 to 0.19 .

In this study, the resilient modulus values obtained from the triaxial test are used to estimate the structural layer coefficients by using the formula provided in the 1993 AASHTO Guide for Design of Pavement Structures [12] for granular base layers, $a_{2}$. The predicted structural layer coefficients for the untreated 7-day cured HFA specimen ranged from 0.08 to 0.16 . The predicted structural layer coefficient values of geogrid-stabilized 7-day cured HFA specimen ranged from 0.09 to 0.19 . It is important to note that the specimens in this study were not cured for 28 days. It is believed that the low structural layer coefficients of the specimens result from the early stages of the pozzolanic reaction. 


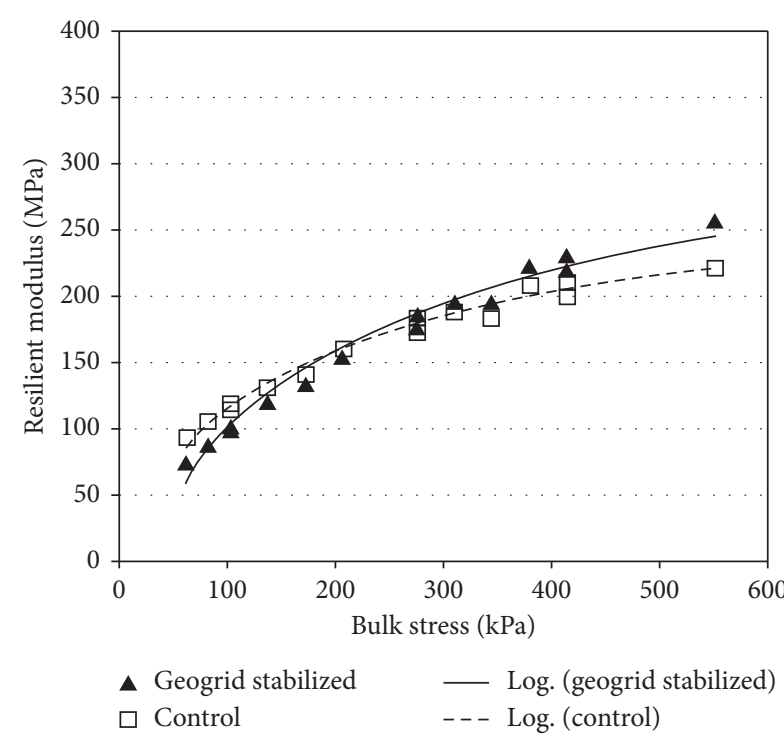

(a)

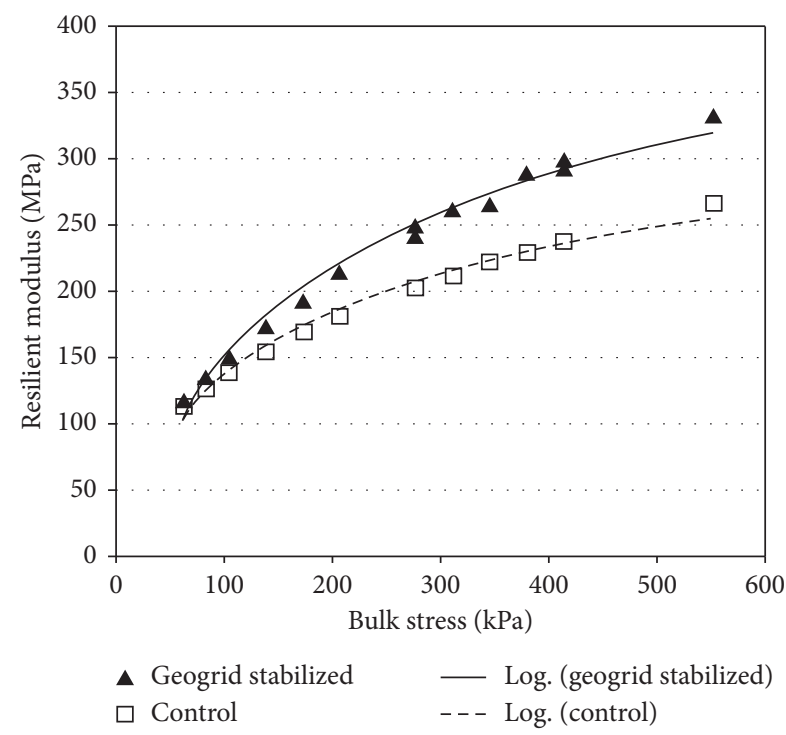

(b)

Figure 3: Resilient modulus from AASHTO T307 test. (a) Results of 0-day cured samples. (b) Results of 7-day cured samples.

2.2. Quick Shear Test. An interesting behavior can readily be seen when looking at the results of the quick shear test. The quick shear test is prescribed in AASHTO T307 as a simple shear controlled by the rate of axial deformation (1\% per minute up to $5 \%$ strain) following the 15 stress sequences of the repeated load testing. The test is performed at a confining pressure of $34.47 \mathrm{kPa}$. Figure 4 graphically depicts the results of this test and demonstrates the positive influence of the geogrid. The geogrid increased the strength by $23 \%(730 \mathrm{kPa}$ vs. $592 \mathrm{kPa}$ ). Also noteworthy is the fact that the geogrid extends the strain-carrying capability by 25 percent or better. The curing time has little effect on the results, although in both cases (stabilized and unstabilized), the result of the 7day cure specimen was a slightly higher maximum stress at a slightly lower failure strain (thus, moderately stiffer).

\subsection{Repeated Load Permanent Deformation (NCHRP 598).}

The permanent deformation test was conducted in accordance with procedures documented in NCHRP Report no. 598. The results of the NCHRP 598 testing are graphically depicted in Figure 5. The NCHRP 598 test specifies 1,000 cycles of the axial load be applied in a step-sequence of axial stress $(69,138,276,413,551,689,827,965,1100$, and $1240 \mathrm{kPa}$ ), all at a constant confining pressure of $103 \mathrm{kPa}$. This translates into 10,000 cycles of loading to complete the test. The axial strain is monitored throughout each test. If an axial strain of 10 percent is reached prior to completion of the regimen of 10,000 cycles, the specimen is considered to have failed, and the test is halted. This test is intended to serve as a "torture" test for aggregate base layers.

Because of the moisture-density profile of the aggregate material, the Control nearly withstood the tortures of the test, crumbling almost instantaneously as the axial stress approached $1240 \mathrm{kPa}$. The geogrid-stabilized specimen exceeded 10\% strain during the test. As such, the testing continued at the highest axial stress $(1240 \mathrm{kPa})$ until $10 \%$ strain was reached, or an additional 10,000 cycles, whichever came first.

As shown in Figure 5, the untreated specimen exhibits a quick sudden failure after the specimen reached $2 \%$ axial strain, whereas geogrid stabilization prevents brittle failure. The result indicates the cementitious bonds of HFA were broken as strain levels increased. The benefit is the resistance to long-term permanent deformation or rutting. The stabilized specimen withstood an additional 7,140 cycles of load at this highest axial stress level, indicating a positive influence of the geogrid.

2.4. Discussion of Laboratory Tests. These results highlight the fact that resilient modulus testing can be used to characterize HFA for use as artificial base course aggregates. Although resilient modulus curves for mechanically stabilized and unbound crushed limestone specimen were similar, repeated load permanent deformation tests show that the inclusion of a triangular aperture geogrid has a positive effect on permanent deformation behavior. Laboratory tests confirmed that there is no direct correlation between AASHTO layer coefficients for HFA and the structural layer coefficient that needs to be adjusted to account for long-term performance using field performance testing.

\section{Field Performance Testing}

The field performance testing program involved static and cyclic plate load tests. Figure 6 illustrates the field conditions and material for the test sections at the project site located in Iowa.

The static plate load test is utilized to determine the asconstructed unit load deflection relationship, while the cyclic plate load test is used to determine field strength values. The static plate load tests were conducted in general accordance with AASHTO T-222. The groundwater surface was 


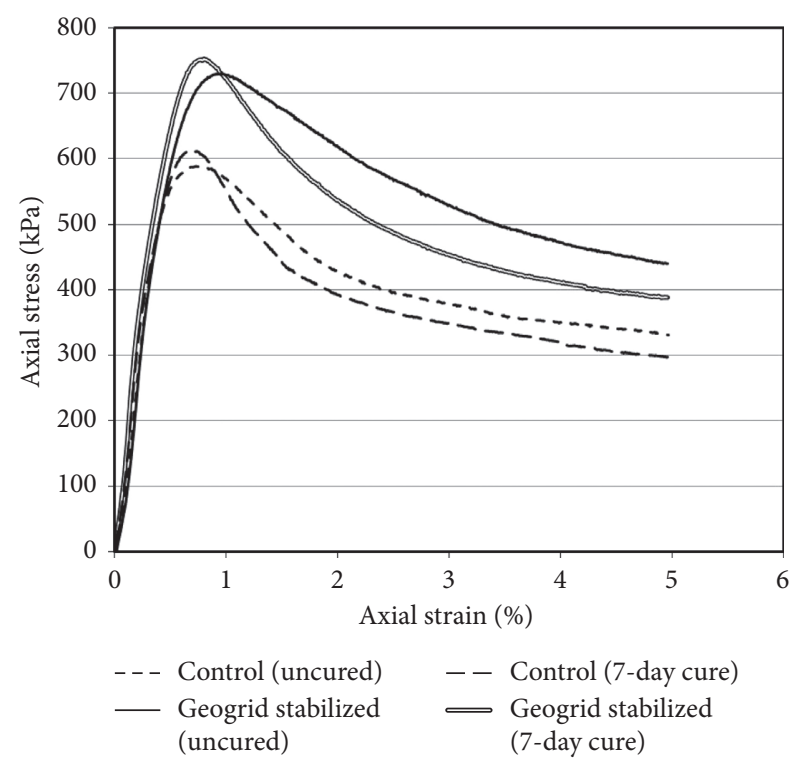

FIgURE 4: Quick shear results from the AASHTO T307 test.

reportedly 6 to 7 feet below the existing ground surface. The native subgrade material at the surface was sandy silt based on visual classification. The CBR values for the 7-day cured HFA sections were about $24 \%$, while the 4 - to 6 -hour cured HFA CBR values were 7 to $16 \%$. Compared to the laboratory CBR values (Figure 2), the field CBR values are about 50\% lower, which is not uncommon when relating the laboratory to the field.

For this study, a 300-millimeter diameter flat plate was selected as the basis of performance verification. Based on heavy equipment loading over some portions of the site, the cyclic loading regime was selected to be between 0 and $689 \mathrm{kPa}$. The plate footprint and stress regime simulate construction equipment loading. This loading regime was selected to help demonstrate the ability of the geogrid to minimize dynamic deflection. Laboratory testing demonstrated that these loading conditions result in particle breakdown and premature shear failure of unstabilized HFA C-stone. Results from the field performance tests were more distinguishing than the performance differences identified from laboratory tests presented earlier.

Three different sections were tested on the project including the following:

Test item 1: 200 millimeters of HFA over the native subgrade placed 4-6 hours prior to testing

Test item 2: 200 millimeters of HFA stabilized with a triangular aperture geogrid placed about 7 days prior to testing

Test item 3: 200 millimeters of HFA over native subgrade placed 28 days prior to testing

3.1. Cyclic Plate Load Test. In addition to the static plate load tests, cyclic tests were performed on all sections. The cyclic tests were set up to simulate 40 or 100 passes of a loaded truck with $689 \mathrm{kPa}$ tire pressures. Results show the relationship between the cycle number and permanent and recoverable deflection at the surface. Key parameters derived from this testing include the overall permanent deflection after 40 or 100 cycles and the in situ resilient modulus. In situ resilient modulus was calculated using the following:

$$
M_{\text {Rin-situ@689kPa }}=\frac{\left(1-v^{2}\right) \sigma_{o} a}{\Delta \mathrm{d}} f,
$$

where $v$ is Poisson's ratio (assumed to be 0.3 ), $\sigma_{\mathrm{o}}$ is the cyclic stress, $a$ is the plate radius, $f$ is the plate rigidity factor (assumed to be 2 for uniform stress distribution), and $\Delta \mathrm{d}$ is the resilient deformation (during unloading).

Figure 7 compares the cyclic plate load test results of each item. It should be noted that item 2 was cured for 7 days but was stabilized with geogrid and item 3 was cured for 28 days. The result shows that item 1 has an initial average displacement of $17 \mathrm{~mm}$ after 10 load cycles, whereas 28-day cured item 3 has only $7.2 \mathrm{~mm}$ of an initial displacement at the same load cycles. The result shows the effect of the curing period on the stiffness of HFA C-stone.

The results of item 2 and item 3 show 7-day cured geogrid-stabilized item 2 has greater strength than that of 28-day cured item 3. The cyclic deflection (deformation that would occur as a wheel passes over the section) of item 2 after 100 load cycles is about 6 millimeter, while item 3 exhibited 9 millimeters of deflection at 40 load cycles. This demonstrated that the use of the geogrid would permit faster construction while achieving higher stiffness over the 28-day cured HFA.

3.2. Static Plate Load Test. Static plate load tests were performed on test item 1 and item 2 to determine the in situ modulus of subgrade reaction (also known as "spring" constant or $k$ value) in the unit load range of 0 to $689 \mathrm{kPa}$. The $k$ values reported herein are not adjusted for plate size corrections or bending. These corrections can be determined with additional testing on site but are generally only needed for applications involving pavements. The stress-deflection response in Figure 8 shows that the control section produced about 6 times more permanent deflection than the C-stone + TX160 section.

It is important to note that test item 2 has been cured for 7 days, whereas item 1 was not cured at the time of testing.

The in situ resilient modulus values are determined based on the cyclic plate load test, and the results are summarized in Table 3 with $k$ values obtained from the static plate load test. Results show that the resilient modulus is highest for the 7-day cured geogrid section and lowest for the zero-day cure with no geogrid. This field performance testing conclusively demonstrates that for the selected loading sequence, the geogrid-stabilized HFA will perform well and is significantly better than the control section both in metrics of resilient behavior and permanent deflection. 


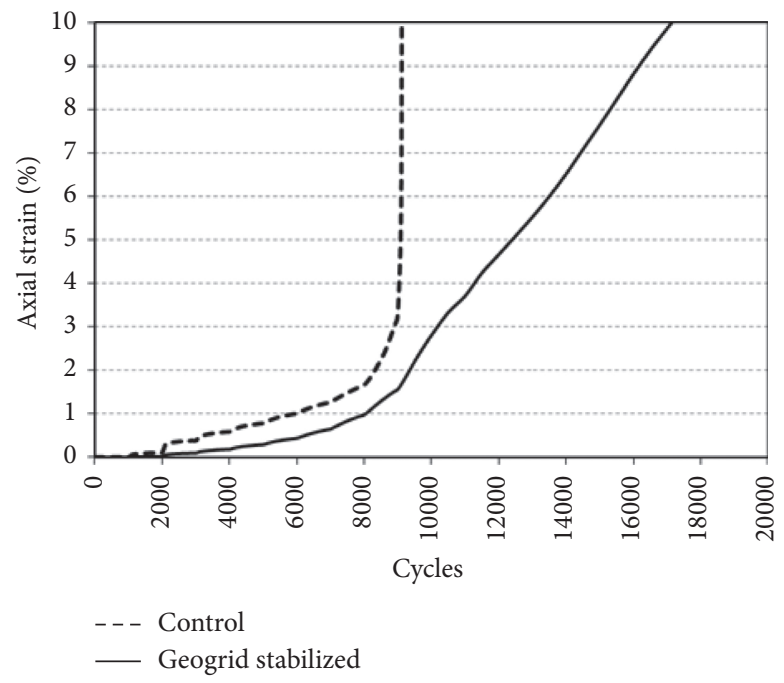

FIGURE 5: Repeated load permanent deformation from NCHRP 598 test (uncured samples).

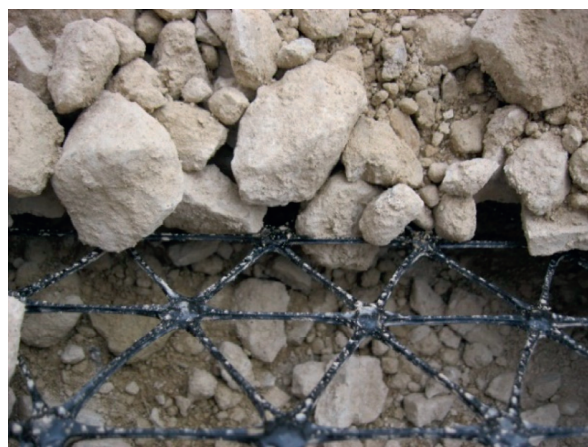

(a)

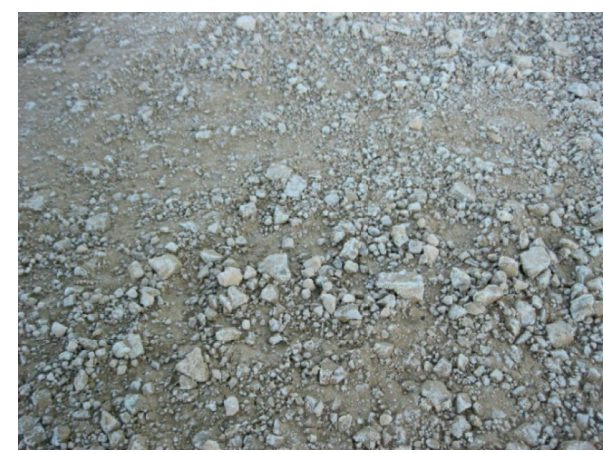

(b)

Figure 6: (a) C-stone and geogrid and (b) C-stone unstabilized test sections.

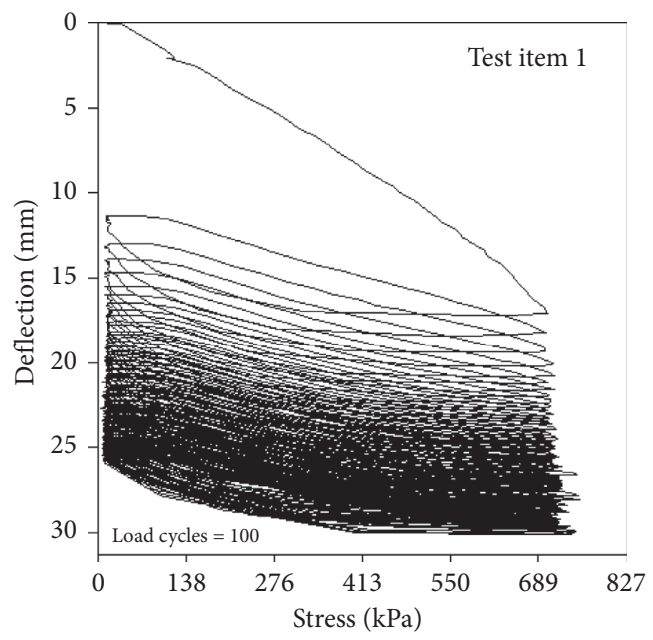

(a)

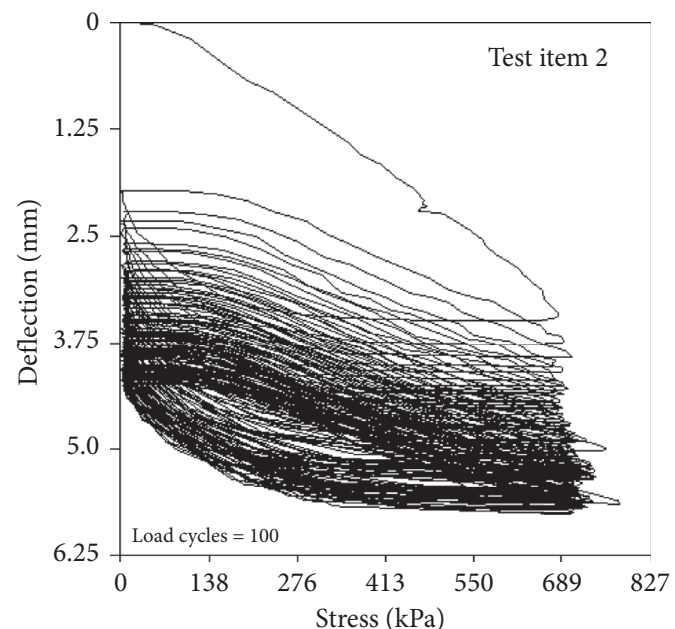

(b)

Figure 7: Continued. 


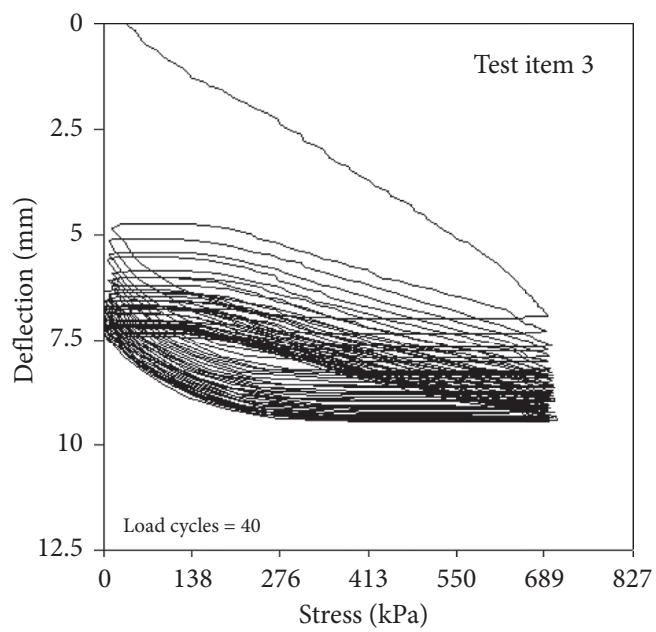

(c)

Figure 7: Cyclic plate load test results. (a) Test item 1: $200 \mathrm{~mm}$ of HFA. (b) Test item 2:200 mm of HFA stabilized with the geogrid (7-day cure). (c) Test item 3: $200 \mathrm{~mm}$ of HFA (28-day cure).

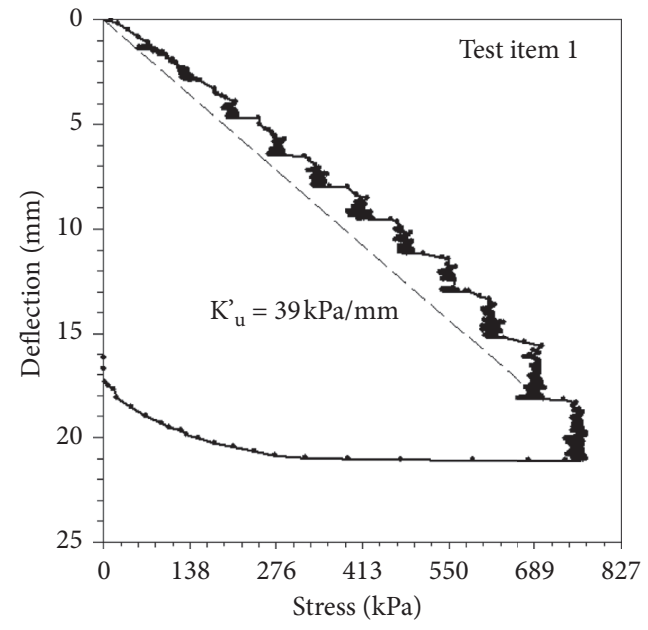

(a)

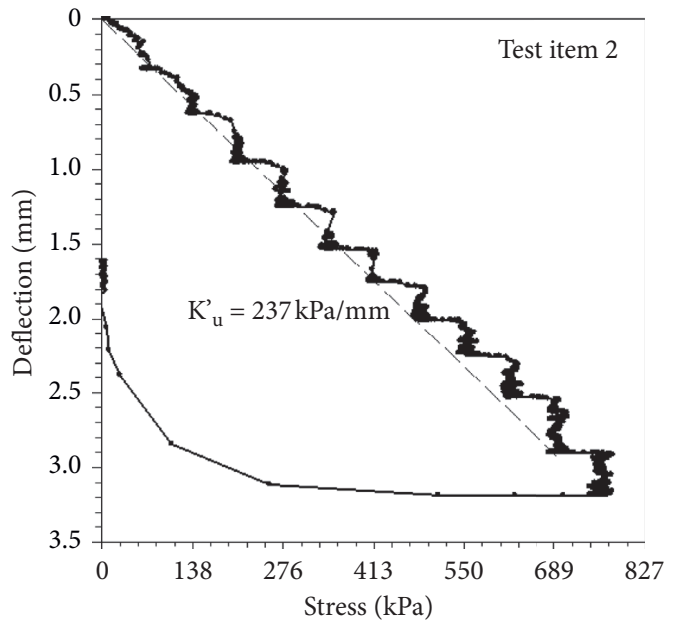

(b)

Figure 8: Static plate load test results of test item 1 and item 2. (a) Test item 1: $200 \mathrm{~mm}$ of HFA. (b) Test item 2: $200 \mathrm{~mm}$ of HFA stabilized with the geogrid (7-day cure).

TABLE 3: In situ resilient modulus and modulus of the subgrade reaction for HFA C-stone.

\begin{tabular}{lcccccc}
\hline $\begin{array}{l}\text { Test } \\
\text { item }\end{array}$ & $\begin{array}{c}\text { Cure } \# \\
\text { days }\end{array}$ & Geogrid & $\begin{array}{c}\text { Modulus of the subgrade } \\
\text { reaction }(\mathrm{kPa} \mathrm{mm})\end{array}$ & $\begin{array}{c}\text { Resilient modulus } \\
(\mathrm{MPa})\end{array}$ & $\begin{array}{c}\text { Permanent deflection-cyclic plate } \\
\text { load test }(\mathrm{mm})^{*}\end{array}$ & $\begin{array}{c}\text { Number of 690 kPa } \\
\text { stress cycles }\end{array}$ \\
\hline 1 & 0.5 & No & 39 & 42 & 11 & 100 \\
2 & 7 & Yes & 237 & 122 & 2 & 100 \\
3 & 28 & No & $-^{* *}$ & 83 & 3 & 40 \\
\hline
\end{tabular}

${ }^{*}$ Total deflection minus seating deflection $($ cycle $=1),{ }^{* *}$ Not tested due to weather delay.

\section{Conclusions}

A series of laboratory and field plate load tests were conducted to characterize HFA and evaluate the in situ performance of the HFA. Laboratory tests were used as an initial assessment of the performance of nontraditional pavement material and then used to predict how this material is expected to perform over time. The laboratory test results provide a fundamental understanding of the behavior of HFA C-stone. Tests currently used for characterizing unbound aggregate material can be used to characterize HFA C-stone. These tests can also be used to evaluate the 
influence of geogrid in HFA C-stone performance. Evaluation of nontraditional base materials may be made through laboratory and field plate load tests as presented in this paper.

The conclusions of the laboratory and field plate load tests described in this paper are as follows:

Long-term strength gain due to the pozzolanic reaction was demonstrated in the laboratory and field plate load tests.

The use of a triangular aperture geogrid was demonstrated as a suitable alternative to the use of chemical stabilization. The in situ resilient modulus value can be increased by more than $30 \%$.

Care should be taken for the use of untreated HFA $\mathrm{C}$-stone as it could exhibit a brittle failure at low strain levels.

Untreated HFA C-stone may not be appropriate as a surface layer for unpaved gravel road as untreated HFA exhibits a brittle failure mode at small axial strain levels. As a result, a crushed quartzite aggregate wearing surface was used in the field prior to the use of this system for a parking lot and construction laydown yard. Additional testing should be performed to better illustrate the interaction between the geogrid and pozzolanic reaction of HFA. Furthermore, the long-term strength gain effects and conditions during spring thaw should be evaluated. The field testing can also be targeted for other selected stress levels to simulate various equipment loading conditions and the number of loading events.

\section{Data Availability}

The laboratory and field data used to support the findings of this study are included within the article.

\section{Conflicts of Interest}

The authors declare that they have no conflicts of interest.

\section{References}

[1] L. Haibin and L. Zhenling, "Recycling utilization patterns of coal mining waste in China," Resources, Conservation and Recycling, vol. 54, no. 2, pp. 1331-1340, 2010.

[2] A. Ebrahimi, B. R. Kootstra, T. B. Edil, and C. H. Benson, "Practical approach for designing flexible pavements using recycled roadway materials as base course," Road Materials and Pavement Design, vol. 13, no. 4, pp. 731-748, 2012.

[3] L. Rafalski and J. Wilczek, "Polish experience with testing of selected shales as material for road base courses," Multiphysical Testing of Soils and Shales, vol. 295, 2012.

[4] S. Akbarnejad, L. J. M. Houben, and A. A. A. Molenaar, "Application of aging methods to evaluate the long-term performance of road bases containing blast furnace slag materials," Road Materials and Pavement Design, vol. 15, no. 3, pp. 488-506, 2014.
[5] M. R. Hainin, Md. M. Aziz, Z. Ali, R. P. Jaya, M. M. ElSergany, and H. Yaacob, "Steel Slag as A Road Construction Material," Jurnal Teknologi, vol. 73, no. 4, 2015.

[6] Z. Adamczyk, M. Grygierek, M. Lupiezowiec, J. Nowak, and E. Strzalkowska, "The effects of mineralogical changes that occur in artificial aggregates," Gospodarka Surowcami Mineralnymi-Mineral Resources Management, vol. 34, no. 2, pp. 37-54, 2018.

[7] Headwater Resources Inc, "(2019) C-Stone technical information," 2019, http://www.flyash.com.

[8] K. Zabielska-Adamska, "Laboratory compaction of fly ash and fly ash with cement additions," Journal of Hazardous Materials, vol. 151, no. 2-3, pp. 481-489, 2008.

[9] K. L. Bergeson and A. G. Barnes, Iowa Thickness Design Guide for Low Volume Roads Using Reclaimed Hydrated Class C Fly Ash Bases, Iowa State University, Ames, Iowa, 1999.

[10] D. J. White, "Reclaimed hydrated fly ash as a geomaterial," Journal of Materials in Civil Engineering, vol. 18, no. 2, pp. 206-213, 2006.

[11] S. P. Senadheera, P. W. Jayawickrama, and A. S. M. A. Rana, "Use of hydrated fly ash as a flexible base material," Transportation Research Record: Journal of the Transportation Research Board, vol. 1546, no. 1, pp. 53-61, 1996.

[12] American Association of State Highway and Transportation Officials, AASHTO Guide for Design of Pavement Structures, American Association of State Highway and Transportation Officials, Washington, D.C., 1993.

[13] D. J. White, P. K. R. Vennapusa, H. H. Gieselman, S. C. Douglas, J. Zhang, and M. H. Wayne, "In-ground dynamic stress measurements for geosynthetic reinforced subgrade/subbase," in Advances In Geotechnical Engineering, Geotechnical Special Publication No. 211, Proceedings of GeoFrontiers 2011, J. Han and D. E. Alzamora, Eds., pp. 4663-4672, 2011.

[14] M. H. Wayne, I. Fraser, B. Reall, and J. Kwon, "Performance verification of a geogrid mechanically stabilized layer," in Proceedings of the 18th International Conference on Soil Mechanics and Geotechnical Engineering, pp. 1381-1384, Paris, France, September 2013. 